\title{
Connexin 43 in the development and progression of breast cancer: What's the connection? (Review)
}

\author{
STEPHANIE L. PHILLIPS ${ }^{1}$, CARLY BESS WILLIAMS ${ }^{2}$, JOELLE N. ZAMBRANO ${ }^{2}$, \\ CHRISTINA J. WILLIAMS ${ }^{2}$ and ELIZABETH S. YEH $^{2}$
}

\begin{abstract}
Departments of ${ }^{1}$ Pediatrics, Division of Pediatric Hematology/Oncology and ${ }^{2}$ Cell and Molecular Pharmacology and Experimental Therapeutics, Medical University of South Carolina, Charleston, SC, USA
\end{abstract}

Received May 23, 2017; Accepted July 17, 2017

DOI: 10.3892/ijo.2017.4114

\begin{abstract}
Connexin 43 is a prominent gap junction protein within normal human breast tissue. Thus far, there have been a number of research studies performed to determine the function of connexin 43 in breast tumor formation and progression. Within primary tumors, research suggests that the level of connexin 43 expression in breast tumors is altered when compared to normal human breast tissue. While some reports indicate that connexin 43 levels decrease, other evidence suggests that connexin 43 levels are increased and protein localization shifts from the plasma membrane to the cytoplasm. In either case, the prevailing theory is that breast tumor cells have reduced gap junction intercellular communication within primary tumors. The current consensus appears to be that the loss of connexin 43 gap junction intercellular communication is an early event in malignancy, with the possibility of gap junction restoration in the event of metastasis. However, additional evidence is needed to support the latter claim. The purpose of this report is to review the connexin 43 literature that describes studies using human tissue samples, in order to evaluate the function of connexin 43 protein in normal human breast tissue as well as the role of connexin 43 in human breast tumor formation and metastatic progression.
\end{abstract}

\section{Contents}

1. Introduction

2. Connexin 43 expression in the normal human breast

3. Connexin 43 expression and breast cancer prognosis

4. The relationship between connexin 43 and tumor initiating cells

5. Cytoplasmic localization of connexin 43 points to decreased GJIC in human breast cancer

Correspondence to: Dr Elizabeth S. Yeh, Department of Cell and Molecular Pharmacology and Experimental Therapeutics, Medical University of South Carolina, Charleston, SC 29425, USA

E-mail: yeh@musc.edu

Key words: connexin 43, gap junction, breast cancer, metastasis
6. Phosphorylated connexin 43 in the progression of breast cancer

7. Increased connexin 43 expression and membrane localization in breast cancer metastasis

8. Conclusions

\section{Introduction}

Gap junctions are intercellular channels that connect the cytoplasm of neighboring cells. These channels allow for crosstalk between cells by regulating the direct intercellular exchange of secondary messengers, small metabolites or inorganic ions, through a process known as gap junction intercellular communication (GJIC). Located at the plasma membrane of the cell, gap junctions are composed of two hemi-channels called connexons, which are assembled from six oligomerized protein subunits called connexins (Fig. 1). The connexin proteins that make up the hemi-channel subunits can be homomeric, consisting of a single protein type of connexin family member, or heteromeric/hetero-multimeric, consisting of two or more connexin family members. When the hemi-channels from two opposing cells come together to form a gap junction pore, the channels can likewise be homotypic, where both hemi-channels are composed of a group of a single type of connexin protein, or heterotypic, containing hemi-channels composed of more than one family member.

In general, connexins and gap junctions are found in numerous cell types throughout the body. To date, 21 different connexins have been identified in humans (1). Expression of these connexin proteins varies among cell types, and cells often express more than one connexin $(2,3)$. Since the initial observation that GJIC is lost in cancer cells, the function of connexins and the role of GJIC in human cancer has been researched and debated (4-6). Since the 1960s, much of this research has centered around the hypothesis that loss of direct intercellular communication is characteristic of cancer cells and is an important driver of tumorigenesis (1).

Connexin $43(\mathrm{Cx} 43)$ is a predominant connexin protein that has been studied in a variety of human cancers including prostate, lung, liver, brain, and breast. Though scientific evidence indicates that connexins, including $C x 43$ have a tumor suppressive role in primary tumors, their role in cancer 


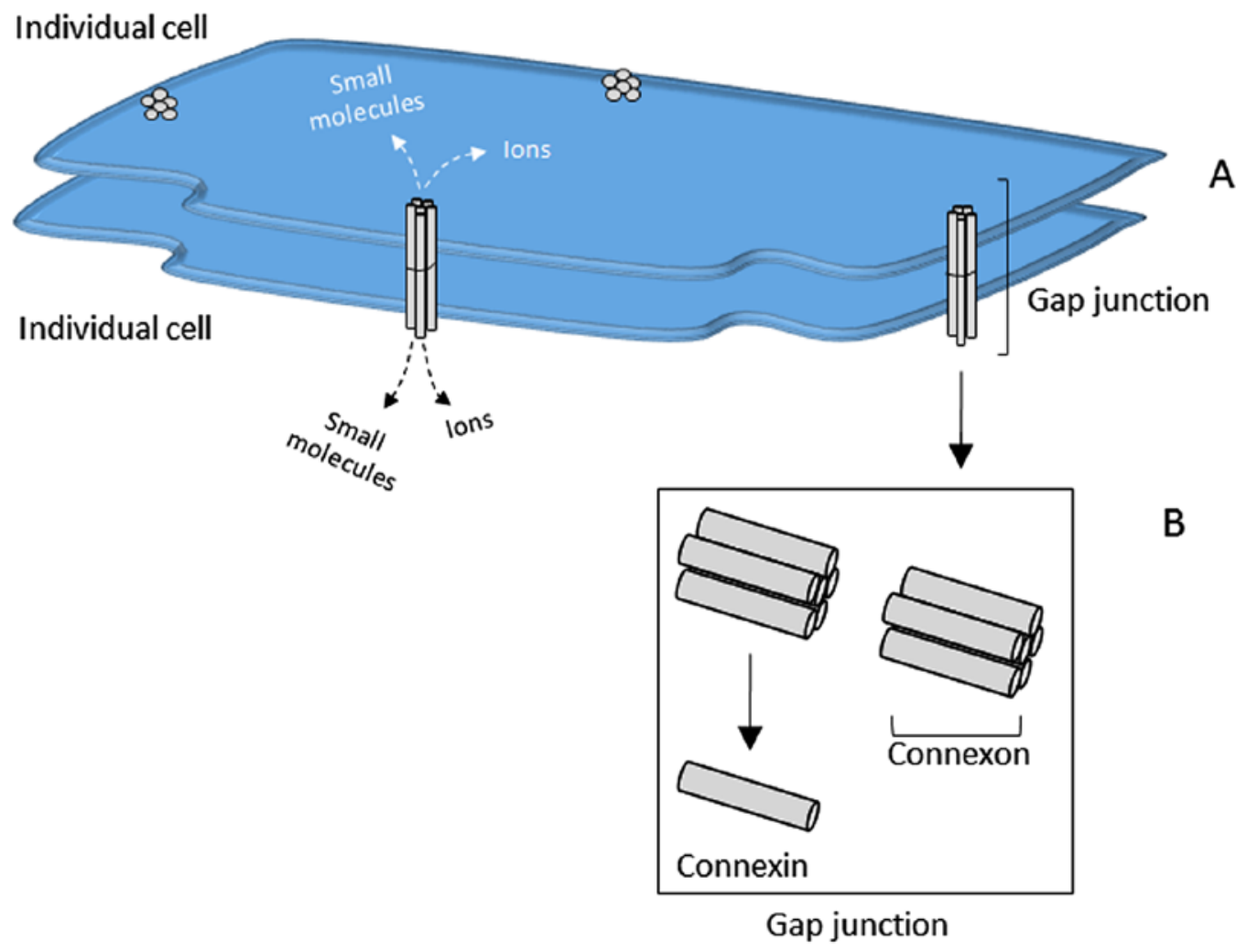

Figure 1. Gap junctions are the structures that allow for communication between individual cells via the direct intercellular exchange of secondary messengers, small metabolites and inorganic ions. Gap junctions are located at the plasma membrane and connect neighboring cells (A). Each gap junction is composed of two hemi-channels known as connexons and each connexon is comprised of six oligomerized protein subunits called connexins (B).

progression and metastasis is quite controversial. Studies that examine human breast cancer tissue suggest that levels of $\mathrm{Cx} 43$ either increase or decrease with cancer stage (7-10). Studies also suggest that $\mathrm{Cx} 43$ localization to gap junctions could play a part in determining disease severity, suggesting that preserving $\mathrm{Cx} 43$ gap junctions could be an important distinction between normal and malignant breast epithelial cells $(7,10,11,23,25-28)$. However, evidence supports both pro- and anti-metastatic roles for $\mathrm{Cx} 43$ and many reports indicate that levels of $\mathrm{Cx} 43$ are both elevated and reduced in breast cancer $(7,9,11-24)$. Consequently, there has been prominent debate in breast cancer regarding whether $\mathrm{Cx} 43$ promotes or inhibits breast cancer progression and metastasis because experimental findings have been somewhat contradictory (11-21).

To date, it appears that in primary breast tumors, overall Cx43 expression is either decreased or increased, with a shift from the protein's normal localization in the plasma membrane within gap junctions to a primarily cytoplasmic localization $(7,10,22,23,25-28)$. In the majority of studies, the consensus is that GJIC is lost within primary tumors. However, in the event of breast cancer metastases, it has been suggested that $\mathrm{Cx} 43$ may become upregulated, which may or may not coincide with a restoration of GJIC (9). Although some consensus, particularly with primary tumors, has been reached, the exact role of $\mathrm{Cx} 43$ in breast cancer, particularly with metastasis, remains elusive. This report seeks to review the role of $\mathrm{Cx} 43$ in human breast and to present the current literature on clinical observations of $\mathrm{Cx} 43$ from studies that focus solely on human breast and breast cancer tissue samples.

\section{Connexin 43 expression in the normal human breast}

The normal, non-malignant, human breast contains a ductal epithelial tree that is composed of a contiguous layer of luminal epithelial cells that is surrounded by an outer layer of basal, myoepithelial cells. In the human breast, two predominant connexins have been described, Cx26 and Cx43 $(7,22,24,25,29)$. Studies to decipher which connexins are expressed in human breast have indicated that $\mathrm{Cx} 26$ and $\mathrm{Cx} 43$ are expressed in individual compartments of the epithelial tree (1-5). Evidence suggests that $\mathrm{Cx} 26$ appears to be predominantly expressed in the luminal epithelium and Cx43 appears to be predominantly expressed in the myoepithelium $(7,22,24,29,30)$.

An initial study by Wilgenbus et al evaluated Cx26, Cx32, and $\mathrm{Cx} 43$ in non-malignant and malignant human tissues, including breast, by immunohistochemical (IHC) analysis and immunoblotting with antibodies directed to each of the connexin proteins (25). Although no discernable expression of $\mathrm{C} \times 26$ and $\mathrm{Cx} 32$ was reported, $\mathrm{C} \times 43$ was found to be expressed in normal breast and the connective tissue of invasive ductal carcinomas of the breast. Following, a study by Pozzi et al evaluated $\mathrm{Cx} 43$ by IHC and reverse transcriptase PCR (RT-PCR) in human breast samples from archived tissues that were obtained from non-pregnant women who had undergone reductive mammoplasty (29). This group identified Cx26, Cx32, and Cx43 in human breast using RT-PCR. However, only $\mathrm{Cx} 43$, localized to myoepithelial cells, was detected by IHC. It is of potential interest to note that $\mathrm{Cx} 43$ expression appears to be predominant when the method of detection for each connexin relies on protein detection using antibodies. 
A follow-up study by Monaghan et al, also using human breast obtained from reduction mammoplasties, confirmed the expression of Cx43 in human breast (24). In this study, IHC, immunoblotting, and RT-PCR were used to evaluate connexins including Cx 26 and $\mathrm{Cx} 43$ in normal breast tissue. IHC staining indicated that $\mathrm{Cx} 43$ is predominantly expressed in the basal myoepithelium of the ducts whereas Cx 26 was detected among the luminal epithelial cells of the ducts. Additional studies by Jamieson et al (22) and Kanczuga-Koda et al (7) confirmed the observation by IHC analysis that $\mathrm{Cx} 43$ is expressed in myoepithelial cells in normal, non-malignant human breast. Furthermore, consensus suggests that Cx43 is localized primarily to the plasma membrane at the lateral surface of myoepithelial cells, presumably at sites of gap junction formation between the myoepithelial cells $(10,22,24,26)$.

In the study by Monaghan et al, normal breast samples were also evaluated for Cx43 by RT-PCR, which confirmed that Cx26 and Cx43 mRNA are present (24). This observation confirms the expression of $\mathrm{Cx} 26$ and $\mathrm{Cx} 43$, but it does not rule out the possibility that the expression signal from either Cx26 or $\mathrm{Cx} 43$ could have originated in the epithelial cells and/or other stromal tissue found in the human breast. However, while Cx43 expression has been reported in the stromal compartment of different types of breast malignancies, it has not been extensively reported in the non-epithelial cell compartment of non-malignant, normal human breast tissue $(22,25)$.

In the study by Monoaghan et al, the authors also purified populations of luminal and basal cells from the normal human breast samples (24). These cells were cultured in vitro and were further evaluated by immunofluorescent (IF) staining and RT-PCR. Isolated basal cell populations showed an increase in Cx43 staining by IF as a function of time in culture. The isolated luminal cell cultures were shown to primarily express Cx26, similar to the in vivo tissue analysis done in this study. By western blotting, $\mathrm{Cx} 43$ but not $\mathrm{Cx} 26$ was present in purified luminal and basal cells. By RT-PCR, Cx43 was more abundant than $\mathrm{Cx} 26$ but still present. Certainly, cell culturing techniques and antibody sensitivity toward individual connexins are among the possibilities suggested for the differences in observations between the studies described here. Additionally, if Cx43 is localized to the plasma membrane of basal myoepithelial cells that border luminal cells, it is potentially logical to presume that both luminal and basal cell types would be positive for $\mathrm{Cx} 43$ protein. Furthermore, multipotent cells may have been present in isolated cell populations, consistent with the observation that $\mathrm{Cx} 43$ expression increased with time. None-the-less, these findings suggest a potential role for $\mathrm{Cx} 43$ in normal human breast function and it follows that a disruption of normal $\mathrm{Cx} 43$ expression and function, potentially between luminal and basal cell populations or the surrounding stroma, could play a role in the development of human breast malignancy.

\section{Connexin 43 expression and breast cancer prognosis}

Since $\mathrm{Cx} 43$ protein expression is relatively abundant in normal human breast myoepithelial cells, studies to determine whether Cx43 expression increases or decreases in breast cancer relative to normal tissue and in relation to cancer stage is a prominent area of investigation. A study by Jamieson et al, sought to evaluate the pattern of expression of $\mathrm{Cx} 26$ and $\mathrm{Cx} 43$ in human breast tumors ( $\mathrm{n}=27,12$ grade 2 tumors and 15 grade 3 tumors) relative to their expression in normal human breast (22). The study authors confirmed $\mathrm{Cx} 43$ in normal human breast tissue localizes to myoepithelial cells and further observed that the stroma of invasive breast carcinomas contained $\mathrm{Cx} 43$-positive cells, unlike the stroma of normal breast tissue. These findings were consistent with earlier studies from Wilgenbus et al who also observed stromal staining of $\mathrm{Cx} 43$ in samples of invasive ductal carcinomas (25). Together, these studies indicate that there is an increase in $\mathrm{Cx} 43$ protein expression in the stroma of invasive breast carcinoma.

Interestingly, the majority of the carcinomas examined at in the study by Jamieson et al showed upregulation of Cx26 and/or Cx43 in carcinoma cells (22). The authors suggest that this marked increase in $\mathrm{Cx} 43$ protein expression levels goes against the hypothesis that GJIC suppresses tumorigenesis. However, if $\mathrm{Cx} 43$ protein is elevated but not localized or functional at the site of gap junctions, then this would suggest either gap junction independent functions for $\mathrm{Cx} 43$ exist or that cancer cells upregulate $\mathrm{Cx} 43$ protein as a compensatory mechanism. It is important to note that 4 out of 12 of the grade 2 tumors and 10 out of 15 grade 3 tumors exhibited carcinoma cells that were $\mathrm{Cx} 43$-positive and the observed staining was mainly diffuse and cytoplasmic. The authors speculate that the ductal epithelial cells of normal human breast express connexins other than $\mathrm{Cx} 26$ or $\mathrm{Cx} 43$ and, that the upregulation of Cx26 and/or Cx43 by the carcinoma cells could alter GJIC between hyperplastic or malignant cells and normal non-cancerous cells (22).

A study by Laird et al reported observations that $\mathrm{Cx} 43$ protein expression is reduced or lost in breast tumors compared to normal breast tissue (23). However, the authors did not observe increased $\mathrm{Cx} 43$ staining in the stromal compartment. In the study by Laird et al, 32 surgical specimens from breast cancer patients who did not receive pre-operative neoadjuvant chemotherapy or radiation therapy were evaluated and compared to adjacent normal tissue from corresponding patient samples (23). Similar to the observations made by Jamieson et al, the non-malignant breast tissue specimens showed moderate to high levels of Cx43 staining (22). The 32 specimens evaluated by Laird et al included malignant samples from ductal carcinoma in situ (DCIS), invasive lobular carcinoma (ILC), and invasive ductal carcinoma (IDC) but no difference in $\mathrm{Cx} 43$ expression was observed between the different histological types and almost all the samples were negative for $\mathrm{Cx} 43$ staining (23). The study authors also used IHC to evaluate estrogen receptor (ER), progesterone receptor (PR), and human epidermal growth factor receptor 2 (HER2) in relation to $\mathrm{Cx} 43$ expression but no correlation to any of the three receptors was observed. Taken together, these observations suggest that loss of Cx43, and presumably GJIC regulated by $\mathrm{Cx} 43$, is a common feature of breast malignancies regardless of histological or receptor defined subtype.

A later study by Kanczuga-Koda et al evaluated a cohort of samples from normal breast $(n=25)$, samples with evidence of dysplasia $(n=40)$, and breast cancer samples including intraductal and invasive carcinomas $(n=29)(7)$. Consistent with earlier observations, the majority of intraductal carcinomas showed little to no immunoreactivity with $\mathrm{Cx} 43$ antibodies suggesting that $\mathrm{Cx} 43$ expression is lost or reduced 
during malignancy $(22,23)$. However, in many of the cases of invasive breast carcinomas that were evaluated in the study by Kanczuga-Koda et al, diffuse cytoplasmic staining was observed suggesting a noticeable amount of $\mathrm{Cx} 43$ protein is present (7). The authors suggest that their findings are consistent with the study by Jamieson et al, who also observed increased Cx43 staining in invasive carcinomas (22). However, it should be noted that in the study by Jamieson et al, the increased Cx43 staining was also associated with increased Cx43 in the tumor stroma (22). Whether or not this distinction is significant, remains to be determined.

A follow-up study by Kanczuga-Koda et al evaluated 71 breast cancer patient samples that only included invasive ductal carcinomas of histological grade 2 or grade 3 (10). While the authors found no association between $\mathrm{Cx} 43$ expression with age, tumor size, or lymph node status, there was a significant positive correlation with $\mathrm{Cx} 43$ expression and histological grade 3 tumors. The authors also evaluated Bak and Bcl-2 expression to follow-up on findings from a study that implicated $\mathrm{Cx} 43$ in apoptosis and found a significant association between $\mathrm{Cx} 43$ expression and the pro-apoptotic protein, Bak (10,31). No association with Cx43 and the anti-apoptotic protein, Bcl-2 was found (10).

A more recent study by Teleki et al sought to evaluate the expression of $\mathrm{Cx} 26, \mathrm{Cx} 32, \mathrm{Cx} 43$, and $\mathrm{Cx} 46$ in breast cancer patient samples prior to and after neoadjuvant chemotherapy (27). In this study, the authors used IHC to evaluate each connexin in samples taken from patients before and after treatment with a variety of chemotherapeutic agents including docetaxel, epirubicin, cyclophosphamide, doxorubicin, viorelbine, fuorouracil, and trastuzumab. These samples were also correlated with Ki67 expression staining and information regarding ER, PR, and HER2 status was available for most of the patient samples. The pre-chemotherapy levels of Cx43 correlated with ER status where high Cx43 expression was more likely to be found in ER-positive samples both before and after chemotherapy treatment. The observation that $\mathrm{Cx} 43$ is associated with ER status was also made in an earlier study by Shipitsin et al (30). Conversely, Cx43 expression negatively correlated with HER2 expression pre-chemotherapy (27). Since previous reports indicate that expression of $\mathrm{Cx} 43$ is hormone responsive, the finding that $\mathrm{Cx} 43$ expression positively correlates with ER status seems reasonable (32-35). However, this finding is contradictory to the study by Laird et al which reported no association between Cx43 and ER or HER2 (23). No relationship between Cx43 and Ki67 was reported as Ki67 staining was not provided for the $\mathrm{Cx} 43$ pre-chemotherapy treatment samples for comparison (27). Together, the observations made in this study by Teleki et al indicate that elevated Cx43 expression corresponds with ER expression but not HER2. Furthermore, Cx43 expression is not changed due to chemotherapy treatment.

An additional observation that can be deduced from the Teleki et al study is that the presence of Cx43-positive cells in both pre-chemotherapy and post-chemotherapy samples suggest that breast cancer cells are positive for $\mathrm{Cx} 43$ (27). This observation is consistent with the study by KanczugaKoda et al which reported a significant level of Cx43 staining in invasive breast carcinoma samples (7). However, no additional measures were taken to distinguish between epithelial and stromal components in breast cancer samples in the former (27). As this study also evaluated Cx26, Cx32, and $\mathrm{Cx} 46$, it seems pertinent to discuss the overall conclusions that the authors made was that a reduced level of $\mathrm{Cx} 26$ post-chemotherapy suggested a better prognosis. Likewise, high levels of Cx46, regardless of whether expression was observed before or after chemotherapy, suggested a better prognosis. These additional observations open up the opportunity for discussion that changing the mixture of connexins expressed in the breast could have significant impact on malignancy and bring into question the potential roles of heterotypic channels as well as hemi-channels in breast cancer.

Almost all of the studies that evaluated Cx43 expression have focused on protein expression detection by IHC. Therefore, Teleki et al performed a study to evaluate connexin gene expression using mRNA platforms (26). The authors also performed an additional protein based analysis on a cohort of tumor microarray (TMA) samples which represented all histological grades of breast cancer. The mRNA analysis was performed separately on data mined from Affymetrix and Illumina platforms but both analyses yielded similar results.

From the Affymetrix analysis, high Cx43 (GJAl) mRNA expression was associated with a reduced relapse-free survival (RFS) and overall survival (OS) in ER-negative patients (26). A study from Stoletov et al confirmed this observation using analysis from the Oncomine database (www. oncomine.org) (28). The analysis by Stoletov et al indicates that higher $\mathrm{Cx} 43$ expression correlated with increased patient death and recurrence. However, in the study by Teleki et al the opposite was true when evaluating distant metastasis-free survival (DMFS) (26). In this case, elevated Cx43 was associated with longer DMFS in the whole patient cohort, in lymph node-negative patients, and ER-positive patients. Similar to these findings, the Illumina-based analysis showed a significant positive association between elevated Cx43 and OS in the whole patient cohort, the ER-positive group, the luminal A group, and the ER-positive cohort that received endocrine therapy. A negative association was reported for OS between elevated Cx43 and ER-negative as well as triple-negative patients.

Interestingly, the $\mathrm{Cx} 43$ protein analysis using TMAs also indicated that elevated $\mathrm{Cx} 43$ expression (scored as 1-3+ vs. 0 for no expression) associated with increased RFS in the whole patient cohort and in histological grade 2 tumors (26). Further analysis of Ki67 staining, as a marker of proliferation, showed low Cx43 stain in high proliferating tumor cells but prominent cytoplasmic $\mathrm{Cx} 43$ staining in low proliferating tumor cells. Though not discussed, it would be interesting to determine if the same $\mathrm{Cx} 43$ protein expression patterns were present for the stromal compartment or if there was any association between Cx43 expression in the stroma and survival or histological grade. Similar to the previous study by Teleki et al, other connexins also held significant prognostic value (27). Whether or not there is a relationship between each connexin, GJIC, and prognosis remains to be determined.

\section{The relationship between connexin 43 and tumor initiating cells}

Breast tumors are composed of a heterogeneous mixture of cells. Many avenues of investigation have argued for the 
existence of a defined subgroup of cancer cells called tumor initiating cells, which are characterized by stem cell-like properties (36-39). These tumor initiating cells, often referred to as cancer stem cells, are defined by their capacity to maintain stem cell phenotypes including self renewal, asymmetrical division, and an ability to promote migration and invasion. Several groups have isolated tumor initiating cells using cell surface markers specific for the normal stem cells of the same organ, and for breast, these cells can be defined by a CD $44^{+}$, CD24- population (36-39).

A study by Shipitsin et al sought to identify genes that are expressed in $\mathrm{CD}_{4} 4^{+}$(stem-like cells) and CD24+ (differentiated) cells (30). The study authors isolated different cell populations, representing $\mathrm{CD} 44^{+}$and $\mathrm{CD} 24^{+}$cells, from human breast tissue obtained from reduction mammoplasty as well as breast tumor samples and then performed gene expression profiling to determine if specific genes were enriched in each population. Interestingly, they found that $\mathrm{Cx} 43$ was significantly expressed in the $\mathrm{CD} 44^{+}$subset. Consequently, the study authors defined $\mathrm{Cx} 43$ as a CD $44^{+}$specific gene.

A follow-up study from the same group by Park et al expanded these findings by looking at breast cancer samples from 4 histological subgroups defined as IDC, IDC with DCIS, DCIS with microinvasion, and DCIS only (40). Consistent with previous findings, Cx43 expression correlated with CD44 expression. The findings from this study indicated that $\mathrm{Cx} 43$ is low in DCIS with microinvasion but significantly higher in IDC with DCIS. This observation was also true for $\mathrm{CD} 44^{+} \mathrm{CD} 24^{-}$-positive cells. Therefore, the correlation of $\mathrm{Cx} 43$ with these two distinct histological subtypes corresponds with findings from the $\mathrm{CD} 44^{+} \mathrm{CD} 24^{-}$cell populations within these same histological subgroups. Altogether, these findings imply that $\mathrm{Cx} 43$ gene expression is enriched in $\mathrm{CD} 44^{+}$cell populations, which further corresponds with specific histological IDC subtypes, implicating Cx43 in breast cancer progression.

\section{Cytoplasmic localization of connexin 43 points to decreased GJIC in human breast cancer}

Many studies have questioned if the loss of GJIC between a potential cancer cell and normal cells is an alteration that leads to a cancer cell transformation (1). There are two methods that have been used as a surrogate for GJIC in static, clinical samples: localization and expression. As discussed, studies evaluating expression have led to findings suggesting both increased and decreased expression levels of $\mathrm{Cx} 43$ protein or mRNA $(7,10,22,23,25-27)$. However, expression levels are not necessarily reflective of protein function, particularly if protein expression is increased. Therefore, $\mathrm{Cx} 43$ localization can also be informative when trying to determine if GJIC is compromised.

In the previously referenced study by Jamieson et al, the localization of $\mathrm{Cx} 26$ and $\mathrm{Cx} 43$ in human breast tumors was evaluated in addition to total expression levels (22). The study confirmed that $\mathrm{Cx} 43$ in normal human breast tissue localizes to the myoepithelial cells with the localization of $\mathrm{Cx} 43$ predominantly on the lateral aspect of the plasma membrane $(10,22,24,26)$. Contrary to this observation, Cx43 localization in 4 of the 12 grade 2 tumors showed predominantly cytoplasmic staining, suggesting that $\mathrm{Cx} 43$ was localized away from sites of gap junctions (22). A similar observation was made in the grade 3 tumors where 10 out of 15 samples showed predominantly cytoplasmic staining of Cx43. Somewhat consistent with this observation, the study by Laird et al determined that $\mathrm{Cx} 43$ expression was predominantly lost, reporting no $\mathrm{Cx} 43$ expression in breast tumors, and consequently no Cx43-positive gap junctions (23).

In the earlier study by Kanczuga-Koda et al, IHC analysis showed primarily cytoplasmic expression of $\mathrm{Cx} 43$ but only in 3 out of 11 intraductal carcinomas (7). The remaining 8 samples were negative for $\mathrm{Cx} 43$, consistent with the Laird et al study (23). Samples of invasive carcinoma $(n=29)$ showed mainly diffuse cytoplasmic staining of $\mathrm{Cx} 43$ in the majority of the samples (26/29) (7). This finding could suggest an upregulation of $\mathrm{Cx} 43$ as tumors progress to an invasive phenotype or that a dominant cell type within the tumor that expressed cytoplasmic Cx43 made up the bulk of invasive tumors. The cytoplasmic localization of $\mathrm{Cx} 43$ suggests that gap junctions are lost in invasive breast carcinomas.

A later study by Kanczuga-Koda et al, also confirmed cytoplasmic expression of $\mathrm{Cx} 43$ but in a larger subset of samples, consistent with their assertion that $\mathrm{Cx} 43$ expression is increased in invasive carcinomas (10). The study authors observed cytoplasmic Cx43 staining in 55 out of $71(\sim 80 \%)$ invasive ductal breast carcinoma samples evaluated. In the remaining 16 samples, 6 samples showed punctate staining of Cx43 in the plasma membrane of the carcinoma cells, presumably representing sites of gap junctions. A punctate plasma membrane staining for $\mathrm{Cx} 43$ was found in a small number of samples (1-2 tumors) and in a small fraction of cells within a total IHC section; a phenomenon that has been reported in other studies as well $(7,22)$. The remaining 10 samples were negative for Cx43 (10). A more recent study by Teleki et al similarly alluded to the idea that $\mathrm{Cx} 43$ becomes more cytoplasmic in tumors with higher levels of proliferation, suggesting a more invasive phenotype (26). All together, these studies confirm the observation that $\mathrm{Cx} 43$ is predominantly cytoplasmic in breast carcinomas, which likely correlates with invasiveness as well as a loss of Cx43 GJIC.

\section{Phosphorylated connexin 43 in the progression of breast cancer}

A major regulatory feature of $\mathrm{Cx} 43$ is that the protein contains at least 16 reported phosphorylation sites (41). Studies indicate that the phosphorylation of $\mathrm{Cx} 43$ regulates the $\mathrm{Cx} 43$ lifecycle including assembly of $\mathrm{Cx} 43$ into gap junctions and formation of gap junction plaques at the plasma membrane as well as trafficking of Cx43 via the endolysosomal and autophagosomal systems. The phospho-mediated regulation of $\mathrm{Cx} 43$ can result in increased or decreased GJIC (1). A study by Gould et al, sought to determine whether $\mathrm{Cx} 43$ phosphorylation correlated with breast cancer stage (42). The researchers developed an antiserum (SA226P) that strongly and selectively reacts with Cx43 phosphorylated on Serine (S) residues at amino acid positions 279 and 282 (S279/S282). Previous studies showed that S279 and S282 are phosphorylated by MAPK signaling through ERK1/2 $(43,44)$. Additional studies indicated that phosphorylation of these residues can either enhance or 


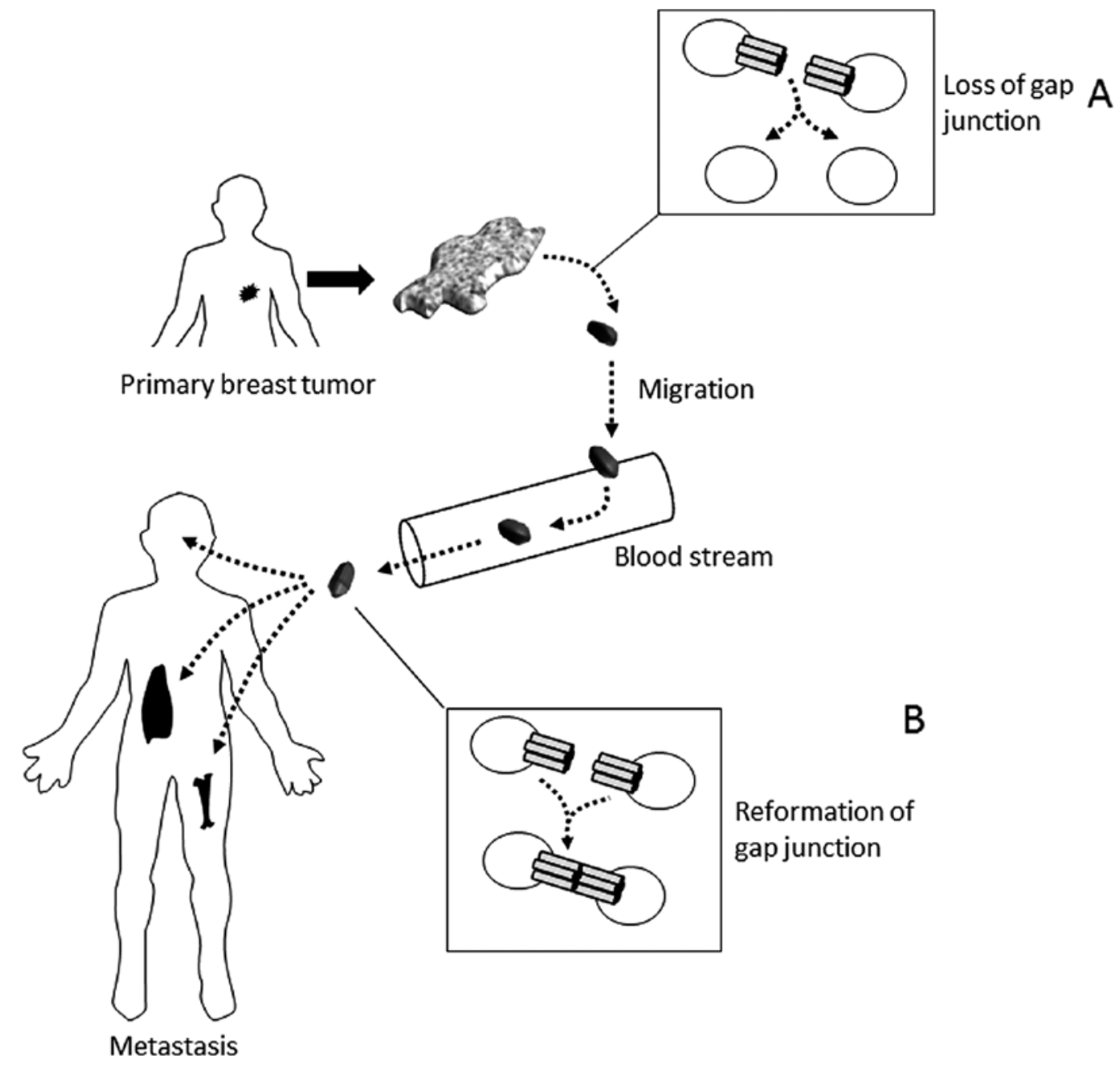

Figure 2. Early stages of breast cancer are thought to be marked by a loss of gap junctions leading to the development of a primary tumor (A). Migration of primary tumor cells into the circulation is part of the inital steps of metastasis. It is thought that gap junction intercellular communication is lost during this initial process and following, a possible reformation of gap junction intercellular communication may occur (B).

inhibit GJIC, depending on the particular experimental cell type (45-53).

In the study by Gould $e t$ al, a total of 98 breast samples were examined, which included tissue from normal adult breast tissue, fibrocystic disease (FCD), fibroadenomas (FA), ductal and lobular carcinomas in situ of all grades, infiltrating ductal carcinomas, infiltrating lobular carcinomas, and infiltrating carcinomas with mixed ductal and lobular features (42). The study authors evaluated phosphorylated $\mathrm{Cx} 43$ using the SA226P antiserum directed at Cx43 phosphorylated at $\mathrm{S} 279 / \mathrm{S} 282$ by IHC and compared these findings with IHC staining of total pan-Cx43. In the normal breast, FCD and FA samples, the SA226P antiserum stained myoepithelial cells in all samples, which was predominantly cytoplasmic and diffuse. Very few cells showed membrane related staining with SA226P. No pan-Cx43 staining was observed in normal breast, which is largely inconsistent with prior studies $(7,10,22,24,26,29)$. Interestingly, staining for pan-Cx43 was also not reported in malignant samples. However, the phospho-Cx43 signal varied depending on the grade of malignancy. While it is difficult to form any conclusions regarding the pan- $\mathrm{Cx} 43 \mathrm{IHC}$ results, the SA226P IHC results suggest that phosphorylation of $\mathrm{Cx} 43$ could vary between normal and malignant breast.
The authors went on to confirm their findings by immunoblotting for pan-Cx43 and phosphorylated $\mathrm{Cx} 43$ using the SA226P antiserum (42). These results showed that the intensity of the bands that reacted with the SA226P antiserum were high in normal breast but were somewhat decreased in papilloma and DCIS samples. A clear increase in phosphorylated Cx43 levels was observed in infiltrating ductal carcinomas, infiltrating lobular carcinomas, and infiltrating carcinomas when compared to papilloma and DCIS samples, suggesting that the amount of phosphorylated $\mathrm{Cx} 43$ increases with increasing disease severity. A similar pattern was observed using the pan-Cx43 antibody. It seems worthwhile to note that because no pan-Cx43 was observed in any of the IHC samples, it may be interesting to revisit these studies using alternative pan-Cx43 antibodies to independently confirm the IHC findings.

\section{Increased connexin 43 expression and membrane localization in breast cancer metastasis}

Studies that evaluated $\mathrm{Cx} 43$ expression and localization uniformly suggest that GJIC is lost during breast malignancy whether it be due to loss of protein expression 
or a predominant localization of $\mathrm{Cx} 43$ in the cytoplasm of tumor cells, away from plasma membrane sites of gap junction formation $(7,10,22,23,25)$. Additional studies have also argued that $\mathrm{Cx} 43$ expression at the mRNA and protein level correlates in a statistically significant manner with poor prognosis (26-28). As a result, many have questioned whether $\mathrm{Cx} 43$ plays a role in metastasis and furthermore, whether $\mathrm{Cx} 43$-regulated GJIC is required for the metastatic process. Studies using breast cancer and mammary tumor cell lines have presented conflicting findings indicating both pro-metastatic and anti-metastatic roles for Cx43 (11-21). Therefore, evaluation of clinically relevant samples would be informative.

A later study by Kanczuga-Koda et al evaluated 51 samples from primary breast cancers that were matched with metastatic lymph node samples taken from the same patient (9). Cytoplasmic Cx43 staining by IHC was observed in $50 \%$ of the primary tumors and 42 of the $51(82.4 \%)$ tumors exhibited some membrane associated Cx43 staining. Interestingly, all the lymph node metastases were positive for $\mathrm{Cx} 43$, even if the primary tumors were negative for $\mathrm{Cx} 43$ staining. The localization of $\mathrm{Cx} 43$ in the lymph node metastases was heterogeneous with cytoplasmic and membrane associated staining. Moreover, the study authors observed a statistically significant increase in Cx43 levels in 18 of the 51 (35.3\%) metastases. Cx26 was also evaluated in this study and while Cx26 was mainly cytoplasmic in both the primary tumor and their metastases, Cx26 levels were higher in the metastases compared with the primary tumor.

As a whole, these findings suggest that $\mathrm{Cx} 43$ likely plays a role in breast cancer metastasis to lymph node and that Cx43-positive tumor cells in lymph node metastases are likely able to localize to sights of gap junctions. These observations are consistent with prior experimental studies that suggest Cx43-mediated GJIC promotes metastasis $(12,14,19)$. It is not known whether the plasma membrane localized Cx43 in the lymph node metastasis samples evaluated in the Kanczuga-Koda et al study are in functional gap junctions, whether the proposed channels are homotypic or heterotypic, or whether hemi-channels could be implicated (9). It is also worth mentioning that it is possible that the tumor cells in the lymph node metastases could be a specific tumor cell subtype that selects for $\mathrm{Cx} 43$ expression, which is a potential explanation for why $100 \%$ of the lymph node metastasis samples were positive for $\mathrm{Cx} 43$ despite some primary tumor samples staining negative for $\mathrm{Cx} 43$.

Additional observations support a role for $\mathrm{Cx} 43$ in mediating interaction with the vasculature during breast cancer metastasis $(28,42)$. The previously described study by Gould et al, whose goal was to evaluate Cx43 phosphorylation in human breast malignancies, showed a strong staining pattern for phosphorylated Cx43, using their SA226P antiserum, in capillary endothelial cells within tumors (42). Along the same lines, Stoletov et al observed small populations of Cx43-positive tumor cells that are in direct contact with blood vessel surfaces (28). While the exact nature of $\mathrm{Cx} 43$ in the vasculature is largely unclear, these studies point to a potential interaction between tumor cells and the vasculature that may be $\mathrm{Cx} 43$-dependent. It is reasonable to speculate that $\mathrm{Cx} 43$ could play a role in intravasation or extravasation during metastasis, but based on these minimal observations, that conclusion seems largely premature.

\section{Conclusions}

Since the expression of $\mathrm{Cx} 43$ was observed in the myoepithelial cells of the human breast over two decades ago, researchers continue to investigate the role of $\mathrm{Cx} 43$ in the development and progression of breast cancer. Though not completely understood, Cx43 gap junctions have a potential mechanistic connection to the development of malignancy in human breast. Some debate still exists regarding the levels of expression of $\mathrm{Cx} 43$ in the malignant progression of breast cancer, however, it seems evident from the literature that loss of GJIC is integral to breast tumor formation. As reviewed here, a general trend seems to be that loss of Cx43 GJIC is an early event in malignancy. Based on at least one study, it may be reasonable to speculate that $\mathrm{Cx} 43$ also plays a role during intravasation or extravasation during metastasis (28). Consequently, we put forth a possible model that is thus far consistent with published reports (Fig. 2), however at this point, the conclusions, in particular with metastasis, may be premature. Though some connection seems apparent, the true role of $\mathrm{Cx} 43$ in breast cancer development and progression remains unclear.

Efforts to therapeutically modulate $\mathrm{Cx} 43$ have largely centered around chemicals that indirectly target $\mathrm{Cx} 43$ through changing membrane dynamics or through direct inhibition of Cx43 gap junction activity $(54,55)$. Since restoring Cx43 gap junction intercellular communication is preferable, at least at early stages of breast cancer development, agents to restore rather than inhibit $\mathrm{Cx} 43$ gap junction communication are needed. At least one such agent is available; a therapeutic peptide called $\alpha$-connexin carboxyl-terminal peptide, which has been tested in several breast cancer cell lines (56). This 25-amino acid length peptide mimics the c-terminal cytoplasmic domain of $\mathrm{Cx} 43$. However, clinical application of peptide agents is somewhat limited due to certain caveats including instability and poor oral availability (57). Furthermore, a highly studied area of $\mathrm{Cx} 43$ research is the noncanonical (i.e., non-gap junction related) functions of $\mathrm{Cx} 43$. Numerous reports demonstrate that the carboxy-terminus (c-terminus) regulatory domain of $\mathrm{Cx} 43$, that is located in the cytoplasm, is a primary site for protein-protein interaction and phosphorylation (58). The c-terminal domain has been reported to contribute to intracellular functions including proliferation, apoptosis, migration, and transcription (58-62). Consequently, two significant issues remain: deciding exactly how to modulate $\mathrm{Cx} 43$ activity and identifying agents that can directly target $\mathrm{Cx} 43$ to restore, rather than inhibit, gap junction intercellular communication. As detection techniques and reagents are refined, the analyses and information gained will continue to improve. Targeted studies to evaluate discreet stages of the metastatic process are needed to further our understanding of $\mathrm{Cx} 43$ 's role in breast cancer progression. Ideally, evaluating individual breast cancer subtypes (e.g., $\mathrm{ER}^{+}, \mathrm{HER} 2^{+}$, and triple-negative) is required for gaining clear insight. Further insight may also be gained as the function of heterotypic gap junctions and hemichannels in breast cancer is revealed, or if non-gap junction functions for $\mathrm{Cx} 43$ and other connexins are identified. Additional studies are 
needed to elucidate the fundamental workings of this protein, which could lead to an enhanced understanding of malignant progression and reveal better potential therapeutic strategies for breast cancer patients.

\section{Acknowledgements}

We would like to thank Dr Jennifer Jaroscak, for her support and encouragement of our research endeavors these past two years. This study was supported, in part, by a grant awarded to E.S.Y. from the METAvivor Research and Support Inc. This study was also supported, in part, by the South Carolina Clinical and Translational Research Insitute, with an academic home at the Medical University of South Carolina, through NIH grant nos. TL1 TR001451 and ULT TR001450, in the form of a training award to C.B.W.

\section{References}

1. Aasen T, Mesnil M, Naus CC, Lampe PD and Laird DW: Gap junctions and cancer: Communicating for 50 years. Nat Rev Cancer 16: 775-788, 2016.

2. Falk MM: Connexin-specific distribution within gap junctions revealed in living cells. J Cell Sci 113: 4109-4120, 2000.

3. Goodenough DA and Paul DL: Gap junctions. Cold Spring Harb Perspect Biol 1: a002576, 2009.

4. Loewenstein WR and Kanno Y: Intercellular communication and the control of tissue growth: Lack of communication between cancer cells. Nature 209: 1248-1249, 1966.

5. Loewenstein WR and Kanno Y: Intercellular communication and tissue growth. I. Cancerous growth. J Cell Biol 33: 225-234, 1967.

6. Fentiman IS and Taylor-Papadimitriou J: Cultured human breast cancer cells lose selectivity in direct intercellular communication. Nature 269: 156-158, 1977.

7. Kańczuga-Koda L, Sulkowska M, Koda M, Reszeć J, Famulski W, Baltaziak M and Sulkowski S: Expression of connexin 43 in breast cancer in comparison with mammary dysplasia and the normal mammary gland. Folia Morphol (Warsz) 62: 439-442, 2003.

8. Kanczuga-Koda L, Sulkowska M, Koda M, Rutkowski R and Sulkowski S: Increased expression of gap junction protein connexin 32 in lymph node metastases of human ductal breast cancer. Folia Histochem Cytobiol 45 (Suppl 1): S175-S180, 2007.

9. Kanczuga-Koda L, Sulkowski S, Lenczewski A, Koda M, Wincewicz A, Baltaziak M and Sulkowska M: Increased expression of connexins 26 and 43 in lymph node metastases of breast cancer. J Clin Pathol 59: 429-433, 2006.

10. Kanczuga-Koda L, Sulkowski S, Tomaszewski J, Koda M, Sulkowska M, Przystupa W, Golaszewska J and Baltaziak M: Connexins 26 and 43 correlate with Bak, but not with Bcl-2 protein in breast cancer. Oncol Rep 14: 325-329, 2005.

11. Carystinos GD, Bier A and Batist G: The role of connexinmediated cell-cell communication in breast cancer metastasis J Mammary Gland Biol Neoplasia 6: 431-440, 2001.

12. Elzarrad MK, Haroon A, Willecke K, Dobrowolski R, Gillespie MN and Al-Mehdi AB: Connexin-43 upregulation in micrometastases and tumor vasculature and its role in tumor cell attachment to pulmonary endothelium. BMC Med 6: 20, 2008.

13. Kandouz M and Batist G: Gap junctions and connexins as therapeutic targets in cancer. Expert Opin Ther Targets 14: 681-692, 2010.

14. Kapoor P, Saunders MM, Li Z, Zhou Z, Sheaffer N, Kunze EL, Samant RS, Welch DR and Donahue HJ: Breast cancer metastatic potential: correlation with increased heterotypic gap junctional intercellular communication between breast cancer cells and osteoblastic cells. Int J Cancer 111: 693-697, 2004

15. Li Z, Zhou Z and Donahue HJ: Alterations in $\mathrm{Cx} 43$ and OB-cadherin affect breast cancer cell metastatic potential. Clin Exp Metastasis 25: 265-272, 2008.

16. LiZ,Zhou Z, Welch DR and Donahue HJ: Expressing connexin 43 in breast cancer cells reduces their metastasis to lungs. Clin Exp Metastasis 25: 893-901, 2008.
17. McLachlan E, Shao Q and Laird DW: Connexins and gap junctions in mammary gland development and breast cancer progression. J Membr Biol 218: 107-121, 2007.

18. Plante I, Stewart MK, Barr K, Allan AL and Laird DW: Cx43 suppresses mammary tumor metastasis to the lung in a $\mathrm{Cx} 43$ mutant mouse model of human disease. Oncogene 30: 1681-1692, 2011.

19. Pollmann MA, Shao Q, Laird DW and Sandig M: Connexin 43 mediated gap junctional communication enhances breast tumor cell diapedesis in culture. Breast Cancer Res 7: R522-R534, 2005.

20. Saunders MM, Seraj MJ, Li Z, Zhou Z, Winter CR, Welch DR and Donahue HJ: Breast cancer metastatic potential correlates with a breakdown in homospecific and heterospecific gap junctional intercellular communication. Cancer Res 61: 1765-1767, 2001.

21. Shishido SN, Delahaye A, Beck A and Nguyen TA: The anticancer effect of PQ1 in the MMTV-PyVT mouse model. Int J Cancer 134: 1474-1483, 2014.

22. Jamieson S, Going JJ, D'Arcy R and George WD: Expression of gap junction proteins connexin 26 and connexin 43 in normal human breast and in breast tumours. J Pathol 184: 37-43, 1998.

23. Laird DW, Fistouris P, Batist G, Alpert L, Huynh HT, Carystinos GD and Alaoui-Jamali MA: Deficiency of connexin43 gap junctions is an independent marker for breast tumors. Cancer Res 59: 4104-4110, 1999.

24. Monaghan P, Clarke C, Perusinghe NP, Moss DW, Chen XY and Evans WH: Gap junction distribution and connexin expression in human breast. Exp Cell Res 223: 29-38, 1996.

25. Wilgenbus KK, Kirkpatrick CJ, Knuechel R, Willecke K and Traub O: Expression of $\mathrm{Cx} 26, \mathrm{Cx} 32$ and $\mathrm{C} \times 43$ gap junction proteins in normal and neoplastic human tissues. Int J Cancer 51: 522-529, 1992.

26. Teleki I, Szasz AM, Maros ME, Gyorffy B, Kulka J, Meggyeshazi N, Kiszner G, Balla P, Samu A and Krenacs T: Correlations of differentially expressed gap junction connexins $\mathrm{Cx} 26, \mathrm{Cx} 30, \mathrm{Cx} 32, \mathrm{Cx} 43$ and $\mathrm{Cx} 46$ with breast cancer progression and prognosis. PLoS One 9: e112541, 2014.

27. Teleki I, Krenacs T, Szasz MA, Kulka J, Wichmann B, Leo C, Papassotiropoulos B, Riemenschnitter C, Moch H and Varga Z: The potential prognostic value of connexin 26 and 46 expression in neoadjuvant-treated breast cancer. BMC Cancer 13: 50, 2013.

28. Stoletov K, Strnadel J, Zardouzian E, Momiyama M, Park FD, Kelber JA, Pizzo DP, Hoffman R, VandenBerg SR and Klemke RL: Role of connexins in metastatic breast cancer and melanoma brain colonization. J Cell Sci 126: 904-913, 2013.

29. Pozzi A, Risek B, Kiang DT, Gilula NB and Kumar NM: Analysis of multiple gap junction gene products in the rodent and human mammary gland. Exp Cell Res 220: 212-219, 1995.

30. Shipitsin M, Campbell LL, Argani P, Weremowicz S, Bloushtain-Qimron N, Yao J, Nikolskaya T, Serebryiskaya T, Beroukhim R, Hu M, et al: Molecular definition of breast tumor heterogeneity. Cancer Cell 11: 259-273, 2007.

31. Krutovskikh VA, Piccoli $\mathrm{C}$ and Yamasaki H: Gap junction intercellular communication propagates cell death in cancerous cells. Oncogene 21: 1989-1999, 2002.

32. Garfield RE, Puri CP and Csapo AI: Endocrine, structural, and functional changes in the uterus during premature labor. Am J Obstet Gynecol 142: 21-27, 1982.

33. Garfield RE, Sims S and Daniel EE: Gap junctions: Their presence and necessity in myometrium during parturition. Science 198: 958-960, 1977.

34. Hendrix EM, Mao SJ, Everson W and Larsen WJ: Myometrial connexin 43 trafficking and gap junction assembly at term and in preterm labor. Mol Reprod Dev 33: 27-38, 1992.

35. Risek B, Guthrie S, Kumar N and Gilula NB: Modulation of gap junction transcript and protein expression during pregnancy in the rat. J Cell Biol 110: 269-282, 1990.

36. Clarke MF and Fuller M: Stem cells and cancer: Two faces of eve. Cell 124: 1111-1115, 2006.

37. Lynch MD, Cariati M and Purushotham AD: Breast cancer, stem cells and prospects for therapy. Breast Cancer Res 8: 211, 2006.

38. Polyak K and Hahn WC: Roots and stems: Stem cells in cancer. Nat Med 12: 296-300, 2006.

39. Wicha MS, Liu S and Dontu G: Cancer stem cells: An old idea - a paradigm shift. Cancer Res 66: 1883-1890; discussion 1895-6, 2006.

40. Park SY, Lee HE, Li H, Shipitsin M, Gelman R and Polyak K: Heterogeneity for stem cell-related markers according to tumor subtype and histologic stage in breast cancer. Clin Cancer Res 16: 876-887, 2010. 
41. Solan JL and Lampe PD: Connexin43 phosphorylation: Structural changes and biological effects. Biochem J 419: 261-272, 2009.

42. Gould VE, Mosquera JM, Leykauf K, Gattuso P, Dürst M and Alonso A: The phosphorylated form of connexin43 is up-regulated in breast hyperplasias and carcinomas and in their neoformed capillaries. Hum Pathol 36: 536-545, 2005.

43. Warn-Cramer BJ, Lampe PD, Kurata WE, Kanemitsu MY, Loo LW, Eckhart W and Lau AF: Characterization of the mitogen-activated protein kinase phosphorylation sites on the connexin-43 gap junction protein. J Biol Chem 271: 3779-3786, 1996.

44. Warn-Cramer BJ, Cottrell GT, Burt JM and Lau AF: Regulation of connexin-43 gap junctional intercellular communication by mitogen-activated protein kinase. J Biol Chem 273: 9188-9196, 1998.

45. Laird DW: The life cycle of a connexin: Gap junction formation, removal, and degradation. J Bioenerg Biomembr 28: 311-318, 1996.

46. Leykauf K, Dürst M and Alonso A: Phosphorylation and subcellular distribution of connexin 43 in normal and stressed cells. Cel Tissue Res 311: 23-30, 2003

47. Melchheier I, von Montfort C, Stuhlmann D, Sies H and Klotz LO Quinone-induced Cdc25A inhibition causes ERK-dependent connexin phosphorylation. Biochem Biophys Res Commun 327: 1016-1023, 2005.

48. Lee KM, Kwon JY, Lee KW and Lee HJ: Ascorbic acid 6-palmitate suppresses gap-junctional intercellular communication through phosphorylation of connexin 43 via activation of the MEK-ERK pathway. Mutat Res 660: 51-56, 2009.

49. Riquelme MA, Burra S, Kar R, Lampe PD and Jiang JX: Mitogenactivated protein kinase (MAPK) activated by prostaglandin E2 phosphorylates connexin 43 and closes osteocytic hemichannels in response to continuous flow shear stress. J Biol Chem 290 28321- 28328, 2015

50. Kang NJ, Lee KM, Kim JH, Lee BK, Kwon JY, Lee KW and Lee HJ: Inhibition of gap junctional intercellular communication by the green tea polyphenol (-)-epigallocatechin gallate in normal rat liver epithelial cells. J Agric Food Chem 56: 10422-10427, 2008.

51. Abdelmohsen K, Sauerbier E, Ale-Agha N, Beier J, Walter P, Galban S, Stuhlmann D, Sies H and Klotz LO: Epidermal growth factor- and stress-induced loss of gap junctional communication is mediated by ERK-1/ERK-2 but not ERK-5 in rat liver epithelial cells. Biochem Biophys Res Commun 364: 313-317, 2007.
52. Munoz JL, Rodriguez-Cruz V, Greco SJ, Ramkissoon SH, Ligon KL and Rameshwar P: Temozolomide resistance in glioblastoma cells occurs partly through epidermal growth factor receptor-mediated induction of connexin 43. Cell Death Dis 5: e1145, 2014.

53. Dubé E, Dufresne J, Chan PT and Cyr DG: Epidermal growth factor regulates connexin 43 in the human epididymis: Role of gap junctions in azoospermia. Hum Reprod 27: 2285-2296, 2012.

54. Evans WH, Bultynck G and Leybaert L: Manipulating connexin communication channels: Use of peptidomimetics and the translational outputs. J Membr Biol 245: 437-449, 2012.

55. De Vuyst E, Boengler K, Antoons G, Sipido KR, Schulz R and Leybaert L: Pharmacological modulation of connexin-formed channels in cardiac pathophysiology. Br J Pharmacol 163: 469-483, 2011.

56. Grek CL, Rhett JM, Bruce JS, Abt MA, Ghatnekar GS and Yeh ES: Targeting connexin 43 with $\alpha$-connexin carboxylterminal (ACT1) peptide enhances the activity of the targeted inhibitors, tamoxifen and lapatinib, in breast cancer: Clinical implication for ACT1. BMC Cancer 15: 296, 2015.

57. Fosgerau K and Hoffmann T: Peptide therapeutics: Current status and future directions. Drug Discov Today 20: 122-128, 2015.

58. Leithe E, Mesnil M and Aasen T: The connexin 43 C-terminus: A tail of many tales. Biochim Biophys Acta 2017 May 16, 2017 (Epub ahead of print). doi: 10.1016/j.bbamem.2017.05.008.

59. Moorby $\mathrm{C}$ and Patel M: Dual functions for connexins: $\mathrm{Cx} 43$ regulates growth independently of gap junction formation. Exp Cell Res 271: 238-248, 2001.

60. Zhang YW, Nakayama K, Nakayama K and Morita I: A novel route for connexin 43 to inhibit cell proliferation: Negative regulation of S-phase kinase-associated protein (Skp 2). Cancer Res 63: 1623-1630, 2003.

61. Behrens J, Kameritsch P, Wallner S, Pohl U and Pogoda K: The carboxyl tail of $\mathrm{Cx} 43$ augments p38 mediated cell migration in a gap junction-independent manner. Eur J Cell Biol 89: 828-838, 2010.

62. Hebert C and Stains JP: An intact connexin43 is required to enhance signaling and gene expression in osteoblast-like cells. J Cell Biochem 114: 2542-2550, 2013. 